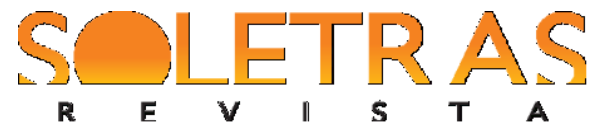

DOSSIÊ-N. 35 - 2018.1 - ISABEL CRISTINA RANGEL MORAES BEZERRA

INÉS KAYON DE MILLER

\title{
Formação de Professores de Línguas: práticas, teorias, diálogos
}

\author{
Isabel Cristina Rangel Moraes Bezerra
}

Inés Kayon de Miller

\begin{abstract}
"A clareza com relação à natureza política e artística da educação tornará o professor um melhor político e um melhor artista. Nós fazemos arte e política quando ajudamos na formação dos estudantes, saibamos disso ou não. Saber o que nós estamos de fato fazendo nos ajuda a fazer isso melhor" (FREIRE).
\end{abstract}

No momento sócio-histórico, político e econômico que o planeta atravessa, há um cenário de fragmentação e liquidez (BAUMAN, 2007), simbolizado na exclusão social, política e econômica de minorias; disputas acirradas pelo poder; projetos identitários em resposta à globalização, à expansão das tecnologias e à sedução para o consumo. A cada dia, pessoas se defrontam com diferenças de todas as ordens, algo inerente ao ser humano, mas que ainda carecem de respeito. Há incoerência, interrupções, dúvidas e insegurança. Nesse contexto, os discursos constroem e reconstroem o mundo social; as posições políticas; as interpretações de dados quantitativos; o que é validado como educação de qualidade nas práticas de professores, assim como no ensino ofertado pelos sistemas público e privado; os benefícios (e malefícios) da globalização para economias e culturas locais; dentre tantas outras questões. Todas trazem, por consequência, grandes desafios para cada esfera de ação cidadã e profissional no campo educacional.

Dessa forma, coloca-se a pergunta óbvia: 'Por que um dossiê sobre a formação de professores?', mais especialmente professores que trabalham ou trabalharão tendo a língua como conteúdo?' Inicialmente, a proposta desse volume surgiu por acreditarmos na riqueza dos encontros como espaços criadores de possibilidades de pensar em práticas variadas para a formação de professores, as quais podem estar apoiadas em diversas teorias de forma a construir diálogos reflexivos. Por isso, nos propomos a tentar responder a essas perguntas ao fazermos conexões entre nossas ideias, as de alguns pensadores e as de autores dos artigos do presente dossiê. Para tanto, o dossiê 35, aliando os discursos provenientes de variadas vertentes de formação de professores para a educação linguística, reúne textos de pesquisadores que tratam da formação e da função social do professor, do papel da escola e de seus agentes na educação para a cidadania, a partir de ações formativas que encaminhem para a construção da justiça social. 


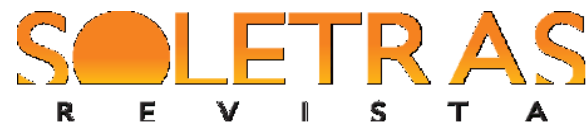

DOSSIÊ-N. 35 - 2018.1 - ISABEL CRISTINA RANGEL MORAES BEZERRA INÉS KAYON DE MILLER

Trabalhar com professores e formadores de professores em processos de desenvolvimento pessoal profissional tem sido, para nós, uma grande motivação. Assim, temos valorizado o trabalho de formadores que vêm adotando paradigmas colaborativos, reflexivos e éticos. Além disso, tal valorização se estende a processos investigativos que também se caracterizam por procurar estabelecer relações de parceria com professores, de reflexão colaborativa movida por questões negociadas nessas parecerias e que se orientam para questões de ordem ética como a responsabilidade e a confiança, dentre outras.

É bastante animador vermos que é possível motivar professores no sentido de problematizarem suas crenças e trabalharem para entender o que acontece em suas salas de aula. Temos percebido que, ao serem convidados, alunos, professores e formadores desejam se envolver em questionamentos e reflexões profundas sobre a qualidade de vida vivenciada na sala de aula e fora dela.

Além do trabalho que temos desenvolvido junto a professores em-serviço, nos satisfaz o que temos realizado na formação inicial de professores de inglês e de português. Tanto na PUC-Rio, Rio de Janeiro, quanto na Faculdade de Formação de Professores-UERJ, São Gonçalo, temos investido sistematicamente na formação inicial, fundamentadas teoricamente pelos princípios ético-inclusivos da Prática Exploratória (SLIMANI-ROLLS, CONSTANTINO; MORAES BEZERRA; COLOMBO GOMES; GUTIERREZ et al, todos neste volume). Priorizamos o trabalho para entender a qualidade de vida na sala de aula e fora dela; buscamos compreender as questões que instigam as pessoas envolvidas; trabalhamos para que todos se desenvolvam em uma ação colaborativa na construção de saberes sobre ensinar e aprender, sobre estar no mundo social, sobre discursos de poder e de resistência; e integramos o trabalho para entender as atividades pedagógicas /profissionais, buscando a sustentabilidade desse trabalho.

Acreditamos que o agir pedagógico, de professoras e professores de línguas, possa trazer uma grande colaboração para a transformação do ensino e da aprendizagem, para o enfrentamento e a superação de desafios no âmbito da educação linguística e de suas práticas tanto em contextos escolares diversos, quanto no âmbito macro da sociedade. Afinal, como apontou Giroux,

É importante enfatizar que os professores devem assumir responsabilidade ativa pelo levantamento de questões sérias acerca do que ensinam, como devem ensinar e quais são as metas mais amplas pelas quais estão lutando (GIROUX, 1997, p. 161). 


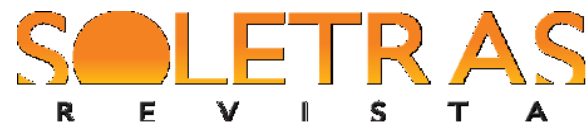

DOSSIÊ-N. 35 - 2018.1 - ISABEL CRISTINA RANGEL MORAES BEZERRA INÉS KAYON DE MILLER

Ou seja, trata-se de o professor assumir seu lugar, ou a identidade, de intelectual transformador, de agente reflexivo, recusando a identidade de técnico especializado dentro da burocracia escolar apenas responsável pela administração e implementação de currículos (GIROUX, 1997). Essa é uma ameaça que, ainda, ronda nossas instituições escolares, em especial com a homologação da Base Nacional Comum Curricular (BRASIL, 2017), que vem acompanhada de cartilhas para a sua implementação nos espaços escolares. Nas palavras da professora Fernanda C. Liberali neste dossiê:

[...] a BNCC não me parece cumprir o papel reflexivo que aponto acima. Seu processo de realização foi traçado em meio a um caos político e ideológico que tornou seu resultado muito mais um objeto de disputa política em um país cindido por brigas e oposições intransponíveis, mas que não respondem ao que se pretende ao criar uma base para a formação de alunos, educadores e formadores (Entrevista à revista Soletras, 2018, p. 21-22).

A questão referida por Liberali ratifica o que Zeichner (1993, p.16) postulou acerca dos professores como profissionais que "devem desempenhar um papel ativo na formação tanto dos propósitos e objetivos do seu trabalho, como dos meios para os atingir; isto é o reconhecimento de que o ensino precisa voltar para as mãos do professor".

Há uma década, Allwright (2008, p.134), já identificava uma mensagem contraditória na formação inicial do professor de línguas em vários países: de um lado, o apontar explícito de que o ensino de línguas é um esforço interpessoal e humano; de outro, mais implícito, de que o fator que realmente importa é o domínio da técnica na construção da competência de ensinar. Como, então, seguir o caminho inverso dessa tendência que tem efeitos deletérios para a prática docente e para a qualidade de vida em sala de aula, em especial gerando burn-out no professor, em formação inicial ou continuada, que não 'domina a técnica'? É ainda Allwright (2008) que complementa: o fato de professores se preocuparem com a qualidade técnica de seu ensino faz com que percam de vista a humanidade que é o cerne dessa prática para o resto de suas vidas. Para que professores em formação inicial não enveredem por esse caminho, algumas práticas podem ser identificadas, por exemplo, em Moraes Bezerra, neste volume, que trata da formação inicial reflexiva atenta à vida na sala de aula, abordando uma formação em que se encoraja a reflexão, o ouvir atentamente as vozes de pequenos aprendizes de língua inglesa, no Ensino Fundamental I. 


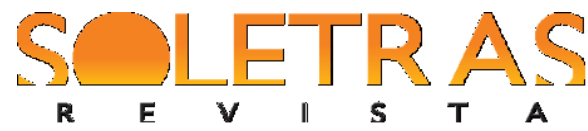

DOSSIÊ-N. 35 - 2018.1 - ISABEL CRISTINA RANGEL MORAES BEZERRA INÉS KAYON DE MILLER

Ainda nessa linha, Constantino e Slimani-Rolls refletem sobre discursos que configuram o que é um bom ensino e um ensino de qualidade, informados pela política neoliberal e pela gestão de práticas educacionais. As autoras discutem a possibilidade de construção de pedagogias locais, mais reflexivas e sensíveis ao contexto, sem a ênfase na qualidade da técnica, considerando a dificuldade de professores traduzirem a pesquisa de base acadêmica para a prática cotidiana. Reafirmam, contudo, a necessidade de o professor ser pesquisador de sua prática, trazendo suas questões como forma de empoderamento através do trabalho colaborativo e reflexivo, conforme a abordagem da Prática Exploratória.

A qualidade de vida, assim como o empoderamento do professor e dos alunos, é abordada por Gutierrez, Slimani-Rolls e Rowel. Isso é feito em um contexto em que o recurso do feedback escrito, oferecido por colegas de classe às produções de estudantes do curso superior, ajuda esses estudantes que precisavam aprender o gênero revisão de literatura para serem aprovados. O processo reflexivo e colaborativo construído coletivamente ajudou os aprendizes a se apropriarem de seu processo de ensino. A professora também se beneficiou, pois conseguiu aprender com os alunos e com os colegas que a ajudaram a instaurar uma prática reflexiva, priorizando a qualidade de vida para fundamentar o ensinar-aprender, não a técnica.

Por tudo o que foi problematizado até agora, ousamos dizer que o professor de línguas tem atuação vital. Se, durante o processo formativo, a língua é entendida como estrutura apenas (algo ainda 'vivo' em muitas salas de aula'), pouco ou quase nada do fazer desse profissional tem o potencial transformador. Abre-se uma via de mão dupla para a transformação de si e para a transformação do outro se já foi ou estiver sendo incorporado à prática docente o entendimento de que se age socialmente através da língua em diferentes situações e por meio de diversos gêneros que mediam a ação humana no mundo social. Nesse sentido, constrói-se com o aprendiz um olhar crítico aos discursos concretizados em textos que posicionam pessoas, propõem designs de identidade, trazem agendas diversas, fazendo com que o aprendiz - e o próprio professor - os leia lendo a si mesmo (MENEZES DE SOUZA, 2011).

Trata-se de abrir um espaço discursivo, pela reflexão, sobre pluralidade e ecologia de saberes - na perspectiva de Sousa Santos (2007); de leituras e entendimentos múltiplos que podem coexistir, por se compreender a possibilidade de haver posições enunciativas e interpretativas que derivam de diversas situações em que se encontram os interactantes no mundo social (MENEZES DE SOUZA, 2011). A partir daí é possível gerar sociabilidades mais alinhadas a um entendimento do outro, mais propensas à escuta do outro. Afinal, o discurso 


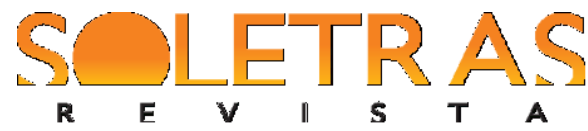

DOSSIÊ-N. 35 - 2018.1 - ISABEL CRISTINA RANGEL MORAES BEZERRA INÉS KAYON DE MILLER

pode construir e reconstruir identidades, bem como o mundo social, em outras bases (MOITA LOPES, 2003) mais solidárias, mais felizes.

Como já apontamos anteriormente (MILLER, MORAES BEZERRA, 2011), a formação docente é um processo permanente. Se, nesse processo educativo, o foco na forma - frases, estruturas - perdurar, o ensino se pautará por alinhamento ao modelo autônomo de letramento (STREET, 2014). Mudar a perspectiva do ensino de língua e da formação do professor do foco em aspectos linguísticos desconectados dos textos que circulam cotidianamente mediando as ações humanas certamente é um caminho a ser trilhado. Nesse sentido, Souza, Simioni e Silva abordam a reflexão sobre norma e variação com alunos do curso de Letras, não apenas como movimento para construção de uma prática docente que se afaste da frase, mas, sobretudo, por conta de reconhecerem a questão ética e social ínsita ao fazer do formador do professor de línguas por se tratar de "um compromisso com o combate a todas as formas de discriminação e sabemos que a discriminação linguística é uma das formas mais perversas de perpetuar as desigualdades sociais" (SOUZA, SIMIONI e SILVA, p. 48). Movimento semelhante foi feito por Santos, que discute o trabalho com frases e com textos em sala de aula de língua portuguesa. $\mathrm{O}$ autor reflete sobre o porquê de professores ainda conduzirem sua prática ora privilegiando conceitos oriundos da gramática tradicional ou normativa; ora mesclando orientações tradicionais, baseadas em conceituação, aplicação e fixação de conceitos, apresentando orientações mais contemporâneas, pois partem do uso, promovem a reflexão e voltam ao uso linguístico. Esse estudo, desenvolvido com professores em formação continuada, identifica práticas híbridas, no que tange a concepções de linguagem, as quais se configuram, de certa forma, incongruentes com o que se discute na academia.

No processo formativo inicial ou continuado, os aspectos teórico-metodológicos sobre língua e ensino que o subjazem podem encaminhar ou não para uma compreensão de língua como discurso, para gêneros discursivos, para diferentes correntes que tratam de letramento[s]. Portanto, é preciso reiterar que a forma como língua e ensino são conduzidos na formação inicial ou continuada reflete-se na proposta das práticas docentes, concretizadas no planejamento das aulas, no trabalho com o texto, no design de atividades. Tais práticas não são, contudo, fixas, podendo ser reconstruídas ou transformadas em interações com colegas em projetos e cursos. É uma questão sobre a qual se pode pensar através estudo feito por Ribas e Tagata. Os autores dirigem o foco para a transformação de concepções acerca da natureza da língua e sobre práticas de ensino trazidas por professores de inglês da rede municipal para um 


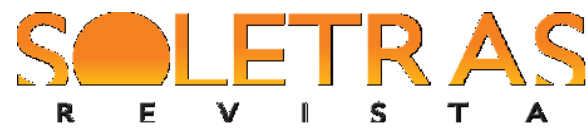

DOSSIÊ-N. 35 - 2018.1 - ISABEL CRISTINA RANGEL MORAES BEZERRA INÉS KAYON DE MILLER

projeto de formação continuada baseado em construtos de novos letramentos e de letramento crítico. A partir daí eles problematizam a construção de sentidos em textos que agregam múltiplas semioses. Ao trabalharem com as necessidades das professoras participantes, os pesquisadores as instigaram a refletir sobre atividades de ensino construídas com base em textos multimodais, assim como sobre a inclusão de tecnologias em suas aulas.

Agindo igualmente para a transformação de práticas e de entendimentos sobre língua, Dalcotivo e Castela trazem uma pesquisa conduzida com professores de espanhol da rede estadual de ensino. Partindo de uma perspectiva interacionista da linguagem e da utilização de TICs, os professores foram encorajados a refletir sobre produção de textos em ambientes virtuais. Ao mesmo tempo, planejavam atividades e refletiam se os enunciados ajudavam os aprendizes na construção do 'projeto do dizer' por meio de indicações sobre o gênero a encaminhar a produção, o tema, a finalidade da produção e as estratégias de produção.

O estudo de Alves e Meira também está alinhado ao entendimento de que a transformação de práticas carece de um encontro entre a teoria e o fazer do qual ambas se alimentam. Ao analisarem um curso de extensão que promoveu a formação continuada de professores de língua portuguesa, as autoras mapeiam e analisam as concepções trazidas pelos docentes sobre sequência didática e sobre como produzi-las. Tais saberes foram interpelados durante o curso, oportunizando a configuração e a reconfiguração de atividades voltadas para o ensino de gêneros textuais no ensino fundamental.

Ferragini aborda a didatização do gênero ensaio literário em uma disciplina ministrada no primeiro período de Letras Português. A autora estabelece um diálogo entre pontos da teorização sobre aprendizagem de Vygotsky e Ausubel, mais especificamente sobre a questão do conhecimento prévio enquanto elemento basilar para a construção de conhecimento, ou melhor, para uma aprendizagem significativa. Pautando-se pela proposta de formação do professor reflexivo, conforme Zeichner (1994), a autora entende que o licenciando, mesmo no início de sua formação, pode considerar aspectos do ensino que poderão ser referência em sua prática futura.

Inspiradas por Vygotsky, que apontava a necessidade de se integrar o fenômeno intelectual ao afetivo no estudo da construção de conhecimentos, trazemos outra questão importante no âmbito da formação docente: diz respeito ao afeto [ou à emoção] construído nas interações através do discurso. O afeto está, a nosso ver, imbricado aos processos cognitivos tanto de aprender a profissão, de aprender a interagir em uma língua estrangeira e ensiná-la, 


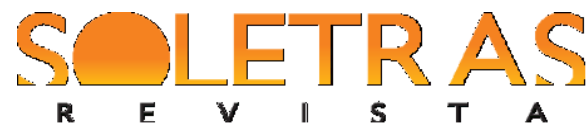

DOSSIÊ-N. 35 - 2018.1 - ISABEL CRISTINA RANGEL MORAES BEZERRA INÉS KAYON DE MILLER

quanto de conduzir uma aula. Colombo Gomes traz o construto Zona de Conforto, articulado ao conceito de face, conforme a tradição goffmaniana, e trata de questões de afeto presentes nas instâncias de produção oral vividas por licenciandos do curso de Letras (Port.-Ing.). A autora percebeu que seus alunos, com medo de errar, limitavam sua interação a estruturas simples. Preocupada com o desenvolvimento do potencial de interação oral dos licenciandos com os quais trabalhava, Colombo Gomes os envolveu em um processo de reflexão sobre a questão da proficiência com base nos pressupostos da Prática Exploratória através de diários reflexivos. Por meio dessa ação, a professora formadora buscava trabalhar a autoimagem dos aprendizes, auxiliando-os a saírem do lugar de quase silêncio em que se colocavam.

Embora não tenha a menção clara às palavras afeto ou emoção, Reis também trata do 'aprender a língua do outro para ensiná-la' em um projeto de formação continuada para professores de inglês. Baseada nos construtos de responsabilização e posicionamento discursivo/subjetivo, a autora analisa relatos escritos pelos professores, a fim de entender como eles significam essa experiência. Através do mapeamento de escolhas lexicais nos textos dos professores, ela resgata elementos que indiciam aspectos emocionais positivos relacionados à transformação de suas práticas.

As pesquisas que fazem parte do volume, de uma forma geral, tratam da formação reflexiva do professor. Já fizemos alusão a um estudo em que o diário reflexivo aparece como elemento gerador da reflexão, outros em que a tarefa de planejar atividades ou uma sequência didática serve, da mesma forma, para praticar o fazer em transformação e para gerar reflexão. Cabe ainda mencionar, por exemplo, a 'instrução ao sósia', descrita e discutida por Modolo, Denardi e Muniz-Oliveira no contexto de estágio supervisionado do curso de Licenciatura em Letras (Port.Ing.). Os licenciandos são encorajados a fazerem perguntas que normalmente não fariam sobre sua prática em construção, reconhecendo o entrelugar de aluno e professor no qual se encontram, seja na universidade, seja no contexto de estágio. Silva e Oliveira, como as autoras anteriores, voltam-se para o campo do estágio supervisionado. Em seu estudo, os autores elegem esse campo como lócus privilegiado para a pesquisa sobre formação e discutem pesquisas feitas sobre o mesmo. Veem o formador como um agente de letramento em relação ao licenciando, preparando-o para a prática profissional e instigando-o a refletir sobre demandas sociais e educacionais.

Breen (2006, p. 206 apud ALWRIGHT, 2008, p. 129), ao tratar das pressões sofridas por professores, aborda a situação global na qual as pressões governamentais repousam sobre 


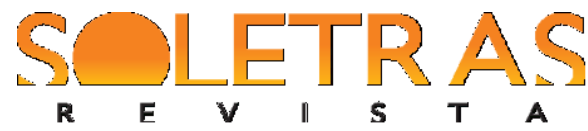

DOSSIÊ-N. 35 - 2018.1 - ISABEL CRISTINA RANGEL MORAES BEZERRA INÉS KAYON DE MILLER

duas suposições. A primeira delas traz o entendimento de que tudo o que os professores conseguiram na educação não é adequado. A segunda é que o estabelecimento de sistemas de vigilância burocrática em relação ao professor, como avaliações padronizadas, melhora a performance dos alunos. A consequência de tal política, ainda segundo Breen (2006, p. 207), é que a 're-capacitação' de professores experientes extremamente capacitados os transformou em gestores de pessoas e de recursos, mas não melhores profissionais. Além disso, provocou um grande êxodo desses professores. Essa é uma questão que temos testemunhado pessoalmente, mas em relação a jovens professores, que não conseguem enfrentar os desafios da profissão. Teríamos como fazer algo para reverter a situação? Talvez uma possibilidade, além dos estudos que já vimos discutindo e que compõem o presente volume, seja analisar algumas experiências vividas em programas subvencionados pelo governo federal para a formação inicial, continuada e complementar de professores de línguas. Referimo-nos ao artigo de Fonseca e Leite, que analisa uma experiência de alunos do PIBID, língua portuguesa. Por meio de autoconfrontação cruzada, os licenciandos refletem sobre suas aulas, ministradas nas escolas conveniadas. Isso é feito ao assistirem aos vídeos de suas aulas, o que lhes permite reinterpretar e reelaborar as atividades produzidas. As emoções desses professores são registradas em falas que revelam surpresas, desconfortos e alegrias diante da realidade de sala de aula.

Outro estudo dessa ordem é proposto por Bispo, que faz uma análise profunda da proposta que originou o Mestrado Profissional em Letras (PROFLETRAS). O autor critica o modelo formativo do programa, questionando a adequação da pesquisa aplicada, indicada aos mestrandos, por se basear na transposição de teorias de forma a promover o desenvolvimento profissional desses mestrandos, docentes da rede pública municipal, estadual ou federal de ensino. Segundo Bispo, para ser mais condizente com o os objetivos do PROFLETAS, deveria ser adotado um modelo de formação profissional do professor reflexivo e não um projeto de intervenção pontual.

Alves e Simões abordam o Plano Nacional de Formação de Professores para a Educação Básica (PARFOR), licenciatura Letras-Inglês. O PARFOR é um programa do governo federal que objetiva oferecer, emergencialmente, cursos para docentes em exercício há pelo menos três anos em uma dada área, porém sem formação específica para essa atuação. Seu público-alvo é constituído de graduados não licenciados, licenciados em área diversa da atuação docente e detentores de diploma do nível médio, na modalidade normal. As vozes dos alunos do 


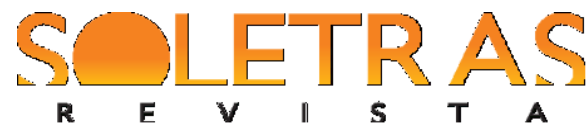

DOSSIÊ-N. 35 - 2018.1 - ISABEL CRISTINA RANGEL MORAES BEZERRA INÉS KAYON DE MILLER

programa, bem como as dos formadores, são trazidas para que sejam analisados pontos positivos e negativos do referido programa.

Retomando e, talvez, expandindo questões que apresentamos inicialmente, queremos ratificar nossa posição de que todo o processo de formação inicial ou continuada de professores deve ser encaminhado no sentido de os professores se entenderem como aqueles que configuram os currículos, ou seja, eles precisam ter uma formação tal que não se vejam manietados por livros didáticos (estes devem ser colaboradores, não a voz que guia tudo o que se faz em sala de aula) ou por discursos neoliberais sobre o que se constitui em um bom ensino de línguas. Esses profissionais precisam selecionar conteúdos necessários para o letramento crítico dos aprendizes, para que esses desenvolvam uma ação discursiva no mundo social que potencialmente colabore para a construção de pontes na direção do outro.

Considerando ainda o cenário mundial já mencionado, no qual muitas vozes falam pelo professor e sobre o professor, mas onde ele não é ouvido de verdade, é preciso questionar quem tem o direito de falar em nome da profissão. Os estudos apresentados nesse volume mostram a força da pesquisa gerada com colegas professores em cursos, oficinas e projetos, trazendo não apenas as dificuldades, mas, e, sobretudo, o que se consegue fazer de transformador em colaboração. É uma forma de resgatar a profissão. Afinal, cada professor tem responsabilidade moral em sua ação. Não temos certezas. Na verdade, ainda temos algumas perguntas para partilhar: 'Quem são os educadores de professores? Apenas os formadores que estão na academia?' 'Quais problemas ou questões no campo da formação do professor de línguas ainda precisam da nossa atenção?' 'Qual é a agenda política que precisa ser construída por formadores, professores, alunos de licenciatura?' 'Será que estamos dando atenção às dimensões relacionais e emocionais da carreira docente que se apresentam desde a formação inicial?' 'Como os professores podem trabalhar para a transformação da educação linguística e para a geração de qualidade de vida, envolvendo alunos, pais e a comunidade educacional?' 'Será que nossas pesquisas no campo da formação docente observam questões éticas com respeito à participação de pessoas e ao que fazemos com tudo o que é gerado nos encontros?' 'As pesquisas que temos desenvolvido têm gerado transformações em escolas, nas vidas de professores e de alunos ou elas apenas fazem parte da obrigação de aumentar a produção acadêmica?' 'Temos trabalhado para a formação de comunidades de aprendizagem profissional de forma a não ficarmos exauridas buscando soluções pessoais para os problemas ou as dificuldades que precisamos enfrentar? Temos realmente pensado em parcerias?' Entendemos

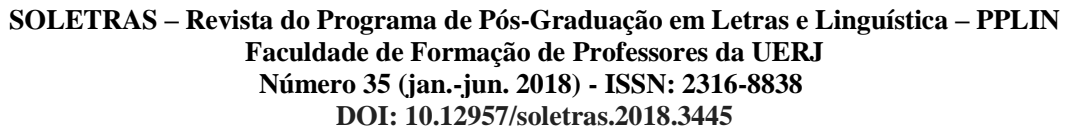




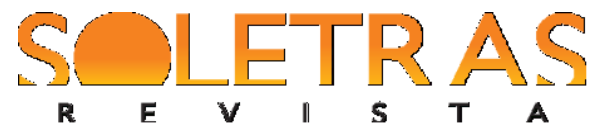

DOSSIÊ-N. 35 - 2018.1 - ISABEL CRISTINA RANGEL MORAES BEZERRA INÉS KAYON DE MILLER

que tais perguntas se fazem necessárias dada a importância da ação docente em qualquer momento da história da humanidade e, em especial, na atualidade, pois, como aponta Bauman

Nada menos que uma "revolução cultural" pode funcionar. Embora os poderes do atual sistema educacional pareçam limitados, e ele próprio seja cada vez mais submetido ao jogo consumista, ainda tem poderes de transformação suficientes para ser considerado um dos fatores promissores para essa revolução (BAUMAN, 2013, p.31).

Temos certeza que ainda há muito por fazer e pesquisar. Em nossa vida de professores, precisamos de esperança. Um projeto educacional e de formação de professores de línguas para a solidariedade, para a diversidade, para a partilha e para a esperança deve considerar o convite de Paulo Freire. Para o autor, é preciso ir ao encontro do outro com a tolerância "que demanda de mim que respeite o diferente, seus sonhos, suas ideias, suas opções, seus gostos, que não o negue só por ser diferente [...] [porque] aprendo com o diferente" (FREIRE, 2016, p. 26).

\section{Referências bibliográficas}

ALLWRIGHT, D. Prioritising the human quality of life in the language classroom: is it asking too much of beginning teachers? In: GIL, G.; VIEIRA-ABRAHÃO, M. H. (Orgs.). Educação de Professores de Linguas - os desafios do formador. Campinas: Pontes Editores, 2008, p.127144.

BAUMAN, Z. Tempos Líquidos. Rio de Janeiro: Jorge Zahar Ed., 2007.

Sobre educação e juventude: conversas com Riccardo Mazzeo. Rio de Janeiro: Jorge Zahar Ed., 2013.

BREEN, M.P. Collegial development in ELT: the interface between global processes and local understandings. In: GIEVE, S. N.; MILLER, I.K. (eds.) Understanding the language classroom. Basingstoke: Palgrave Macmillan, 2006, p. 200-225.

FREIRE, P. Pedagogia da Tolerância. Organização de Ana Maria Araújo Freire. São Paulo: Paz e Terra, 2016.

GIROUX, H. Os professores como intelectuais - rumo a uma pedagogia crítica da aprendizagem. Porto Alegre: Artes Médicas, 1997.

MENEZES DE SOUZA, L. M. T. O professor de inglês e os letramentos do século XXI: métodos ou ética? In: JORDÃO, C. M.; MARTINEZ, J. Z.; HALU, R. J. (Orgs.) Formação Desformatada - práticas com professores de língua inglesa. Campinas: Pontes Editores, 2011, p. 279-303.

STREET, B. V. Letramentos sociais: abordagens críticas do letramento no desenvolvimento, na etnografia e na educação. Tradução Marcos Bagno. São Paulo: Parábola Editorial, 2014.

ZEICHNER, K. M. A formação reflexiva de professores: idéias e práticas. Lisboa: Educa, 1993.

Research on teacher thinking and different views of reflective practice in teaching and teacher education. In: CARLGREN, I.; HANDAL, G.; VAAGE, S. Teachers' minds and actions: research on teachers' thinking and practice. UK: London, The Falmer Press, 1994, p.927. 